\title{
On the use of a CFBG sensor to monitor scarf repairs of composite panels
}

\author{
R. L. Rito, S. L. Ogin, A. D. Crocombe, T. F. Capell, A. R. Sanderson \\ Faculty of Engineering and Physical Sciences, University of Surrey, Guildford, UK \\ Yalin Guo \\ Xi'an Aerospace Composites Research Institute, Xi'an, Shaanxi, P. R. China
}

S. C. Tjin, B. Lin

School of Electrical and Electronic Engineering, Photonics Research Centre, Nanyang Technological

University, Singapore

ABSTRACT: Scarf repairs are often used for damaged composite structures in order to recover the mechanical properties of the original structure. During service, there is the possibility that damage will occur in the repaired region and hence it would be useful to be able to monitor such repairs. This work investigates the use of chirped fibre Bragg grating (CFBG) sensors to monitor the development of damage initiation and growth in the repaired region. The experimental part of the work uses a model system consisting of a scarfrepaired, transparent GFRP beam. During fatigue loading, damage in the form of cracks initiate at the interface between the scarf-repair and the parent material on the tensile face of the beam, and grows within this region. The modulus reduction as a consequence of crack growth has been monitored and finite-element analysis (FEA) has been used to predict this reduction, with reasonable agreement between experiment and modelling. Using the FEA analysis, predictions have been made of the strain changes in the vicinity of the growing damage and the effect that these would have on reflected spectra recorded by a chirped fibre Bragg grating sensor bonded across the scarf repair. The predictions suggest that as the damage develops within the scarf repair, the strain changes will modify the reflected spectra in such a way that the initiation of damage can be detected and the growth of fatigue cracks associated with the scarf repair can be monitored. The predictions are in good qualitative agreement with experimental results.

\section{INTRODUCTION}

Composite materials are used in a wide range of high performance structures and the rapid increase in the use of composites has led to increased interest in composite repair technologies (Breitzan et al. 2009). There are two commonly used types of bonded repairs: the scarf and patch repairs (Ridha et al. 2011). While there has been much interest in predicting the behaviour of scarf repairs under load (Pinto et al. 2010) much less attention has been paid to structural health monitoring of such repairs.

Chirped fibre Bragg grating sensors have been shown to be able to monitor delamination initiation and growth in single-lap joints when embedded within one of the adherends (Palaniappan et al. 2007; Palaniappan et al. 2008; Capell et al. 2009). The purpose of this work is to investigate whether such sensors can be used to monitor the initiation and propagation of damage in a scarf-repaired transparent GFRP specimen subjected to flexural fatigue loading.

\section{DAMAGE ACCUMULATION AND GROWTH - RESULTS AND MODELLING}

\subsection{Experimental procedures}

Figure 1 shows a schematic of a scarf-repaired laminate subjected to 4-point bending load. The composite material considered in this study is a transparent GFRP beam fabricated using 16 plies of 8-harness satin fabric, which was impregnated with an epoxy resin using a wet lay-up technique to produce a transparent laminate.

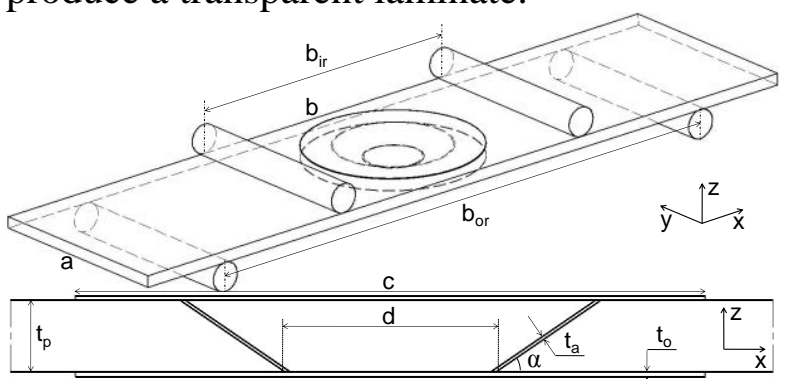

Figure 1. Schematic drawing of the scarf repaired laminate subjected to 4-point bending test. 
The laminate configuration was $\left[0^{\circ} 90^{\circ} / 90^{\circ} 0^{\circ} / 0^{\circ} 90^{\circ} / 90^{\circ} 0^{\circ}\right]_{2 \mathrm{~s}}$ and the length $(b)$, width $(a)$, and thickness $\left(t_{p}\right)$, of the coupons tested were $265 \mathrm{~mm}, 70 \mathrm{~mm}$ and $4 \mathrm{~mm}$, respectively. A conical hole was machined at the centre of the coupon with diameter $(d)$ of $20 \mathrm{~mm}$ on the bottom surface giving a scarf angle $(\alpha)$ of $21.8^{\circ}$. The scarf repair was produced using a stack of the same woven glass fabric, with an overply having a diameter $(c)$ of 60 $\mathrm{mm}$ on the top and bottom surface of the coupon; consequently, the repair had the same fibre volume fraction as the host material. For the 4-point bending test, the two outer rollers were $200 \mathrm{~mm}$ apart, with the two inner rollers $100 \mathrm{~mm}$ apart. When used, the CFBG sensors, having a sensor length of $60 \mathrm{~mm}$, were embedded between the parent coupon material and the overply on the tensile face of the coupon, in the longitudinal direction. Strain gauges were also bonded to the coupons to measure longitudinal strain at the centre of the panel, $5 \mathrm{~mm}$ away from each edge.

\subsubsection{Damage development and stiffness reduction - observations and modelling}

The fatigue cycling was carried out using a computer controlled servo-hydraulic test machine with peak load of $1.5 \mathrm{kN}$, an R-value of 0.1 and a sinousidal waveform with a frequency of $0.5 \mathrm{~Hz}$. Damage developed on the tensile face of the coupon, with a crack which ran through the overply and propagated in a stable manner between the scarf repair and the parent coupon material (see Fig. 2).

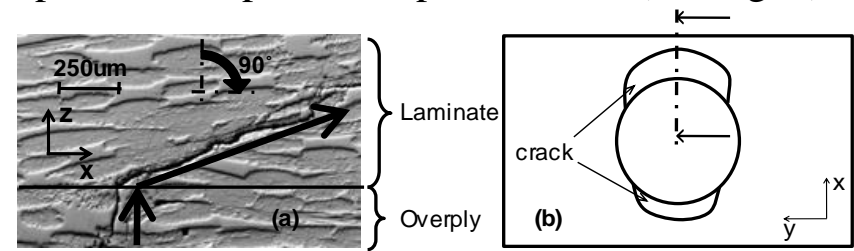

Figure 2. (a) Section photograph of a crack; the arrows show the crack propagation direction. (b) Schematic of two cracks.

Figure 3 shows the propagation of the damage with increasing numbers of load cycles, photographed from the compressive face of the panel (the $h w$ and $l w$ in the figure refers to the high- and low-wavelength ends of the CFBG sensor). It can be seen that in this example the damage nearer the $h w$ end of the optical sensor grew more rapidly.
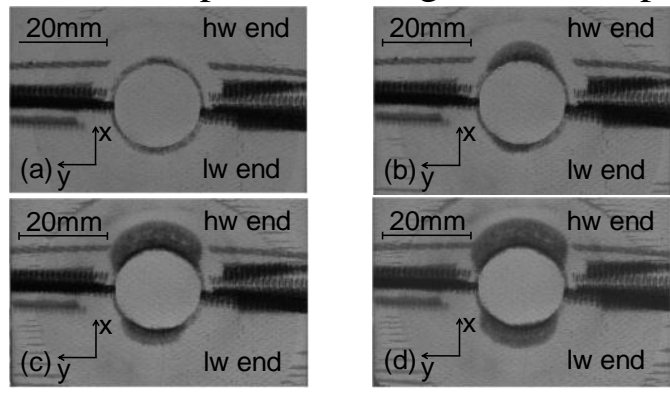

Figure 3. Photographs of the specimen showing different cracks lengths after (a) 1000, (b) 6000, (c) 12000 and (d) 18000 cycles.
The flexural modulus of the coupon was measured as a function of the number of fatigue cycles by interrupting the fatigue tests and loading the coupon quasi-statically, again in four-point bending to $1 \mathrm{kN}$. The flexural modulus could then be derived from the load/strain data, with the strains obtained from the surface bonded strain gauges. Figure 4 shows the modulus as a function of number of cycles; apart from an initial 6\% drop in modulus, the modulus reduced in an approximately linear manner with number of cycles. The modulus reduction was due to the growth of the fatigue damage at the scarf repair/parent material interface which is modelled in the next section.

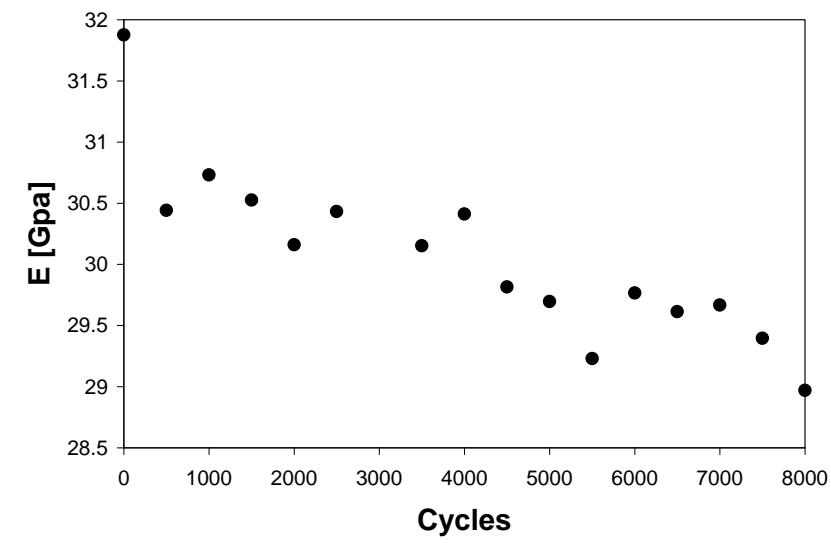

Figure 4. Modulus as a function of number of fatigue cycles.

\subsection{FEA modelling: modulus reduction}

The coupons have been modelled using solid elements with orthotropic material properties. The mechanical properties used in the FEA models for the eight-harness GFRP laminates and the adhesive are shown in Tables 1 and 2 (Kyriazoglou \& Guild 2005).

Table 1. Laminate mechanical properties.

$\begin{array}{lll}\mathrm{E} 1=21000 \mathrm{GPa} & v 12=0.183 & \mathrm{G} 12=3700 \mathrm{MPa} \\ \mathrm{E} 2=21000 \mathrm{GPa} & v 13=0.0305 & \mathrm{G} 13=3500 \mathrm{MPa} \\ \mathrm{E} 3=8550 \mathrm{GPa} & v 23=0.075 & \mathrm{G} 23=3500 \mathrm{MPa}\end{array}$

Table 2. Resin mechanical properties.

$\mathrm{E}=4000 \mathrm{MPa} \quad v=0.36$

Due to symmetry, one quarter of the scarf repaired panel was modelled, with the dimensions used for the experimental work. Five different FE models of the repaired panel were created: one undamaged and four damaged with different projected fatigue crack lengths of $1.7 \mathrm{~mm}, 2.3 \mathrm{~mm}$, $4.0 \mathrm{~mm}$ and $4.7 \mathrm{~mm}$, which correspond to the average crack lengths at 2000, 4000, 6000 and 8000 cycles in Figure 3. Damage was produced by explicitly uncoupling nodes at the adhesive/parent coupon interface (the resin-rich region, $t_{a}$, between the scarf repair and the parent material was taken to be $0.2 \mathrm{~mm}$ thick; see Fig. 1); there was no attempt 
here to predict damage development. Figure 5 shows a schematic of the damaged panel after 8000 cycles with the area of the fatigue crack identified. Measurements were performed on photographs of the damaged area in order to determine the correct geometry for the damage for the FE modelling. This was only possible because of the transparency of the GFRP panel.

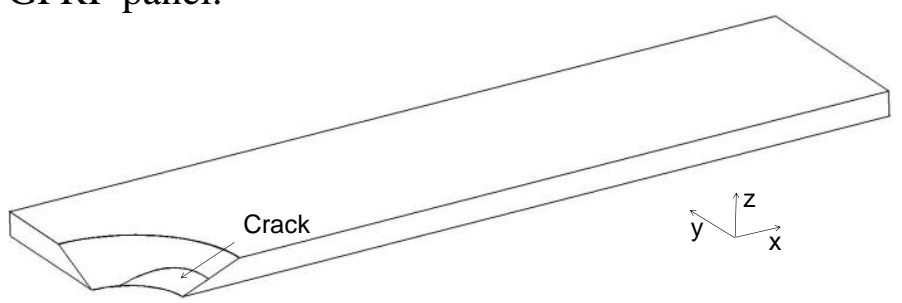

Figure 5. Damaged area geometry after 8000 cycles.

\subsubsection{Undamaged (repaired) coupon}

Figure 6 shows a schematic of the edge view of the specimen along the centre line of the coupon, which is the position of the optical sensor. The 60 $\mathrm{mm}$ sensor extends $20 \mathrm{~mm}$ each side of the scarf repair/parent material interfaces which are at $\mathrm{A}$ and B.

LWend

Figure 6. Schematic of a cross-section through the specimen at the position of the optical sensor.

Figure 7 shows the longitudinal strains at the interface between the parent panel and the overply for a load of $1 \mathrm{kN}$. The maximum strain occurs at distances of 20 and $40 \mathrm{~mm}$ which correspond to the interface between the parent panel and the resin-rich layer at the interface between the scarf repair and the parent coupon. The strains are constant for the parent material until close to the interface with the resinrich region, where the strains rise to high values. The strain is lower within the repaired region itself, probably because of the strain concentration within the resin-rich interface regions. The strain fluctuations at $0 \mathrm{~mm}$ and $60 \mathrm{~mm}$ correspond to load transfer at the ends of the overply.

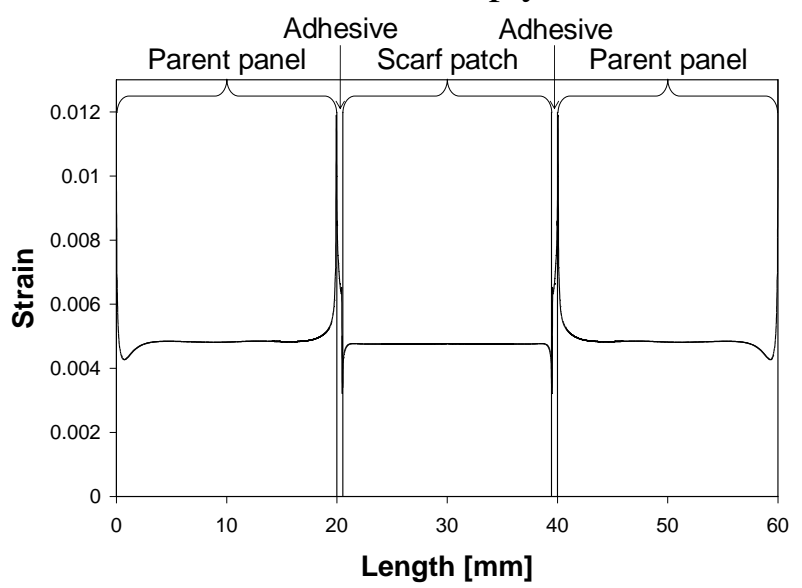

Figure 7. Strain profile for the undamaged (repaired) panel loaded at a load of $1 \mathrm{kN}$.

\subsubsection{Strain distributions for different fatigue crack lengths associated with the scarf repair}

Figure 8 shows the predicted longitudinal strain profiles for different projected fatigue crack lengths for the scarf repaired panel loaded at $1 \mathrm{kN}$. Of particular importance here is the behaviour of the longitudinal strain in the vicinity of the resin-rich interface as the crack length increases. Considering a distance of $15 \mathrm{~mm}$ from the $0 \mathrm{~mm}$ position (which will also be the low-wavelength end of the CFBG sensor), for a load of $1 \mathrm{kN}$, the strain decreases from 0.0036 for a crack length of $1.7 \mathrm{~mm}$ to 0.0007 for a crack length of $4.7 \mathrm{~mm}$.

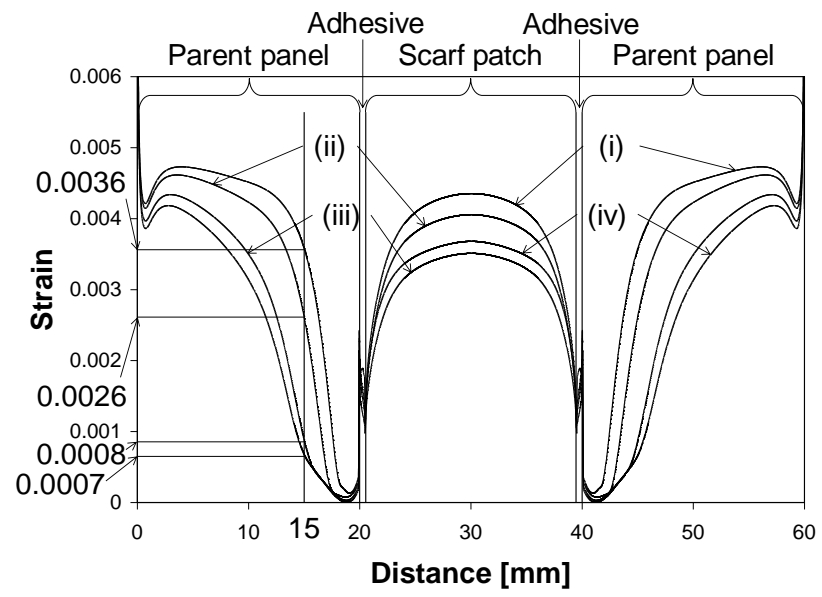

Figure 8. Strain profiles for different degrees of damage - (i) 1.7 , (ii) 2.3 , (iii) 4.0 and (iv) $4.7 \mathrm{~mm}-$ at $1 \mathrm{kN}$ load.

This local reduction in strain occurs because as the fatigue crack increases in length, the panel material close to the resin-rich interface is increasingly shielded - illustrated in Figure 9 by a schematic showing visualisations of (fictitions) lines of force around the crack. These changes in the local strains will have a significant influence on the reflected spectrum of the CFBG sensor (see Section 2.3.4 below).

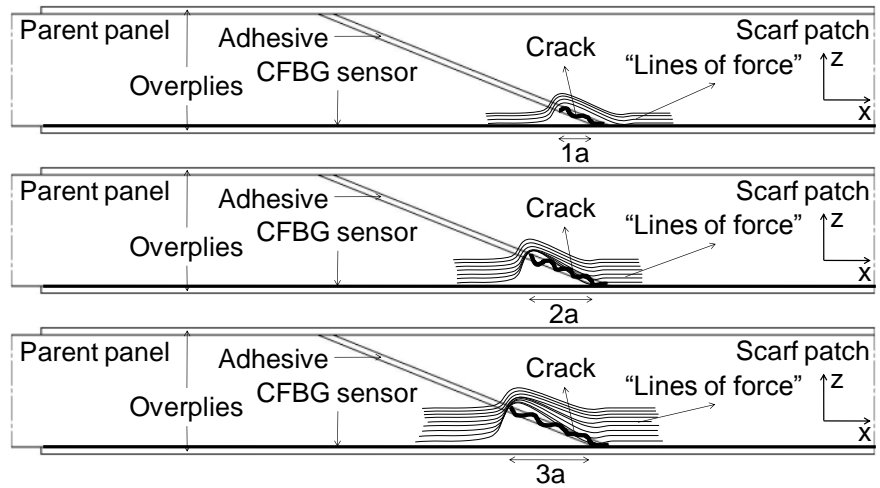

Figure 9. Cross section view of the crack growth showing a visualisation of the variation in the (fictitious) lines of force for different degrees of damage. 


\subsubsection{Modulus reduction due to fatigue crack growth}

The FEA modelling also allows the reduction in the flexural modulus to be predicted as a function of fatigue crack growth. Figure 10 shows the predicted flexural modulus of the repaired panel as the damage progresses, normalised by the initial modulus of the repaired panel without any fatigue damage. The trendline of the experimental data is also plotted in this figure and there is reasonable agreement between the predicted and experimental modulus reductions for the different fatigue crack lengths.

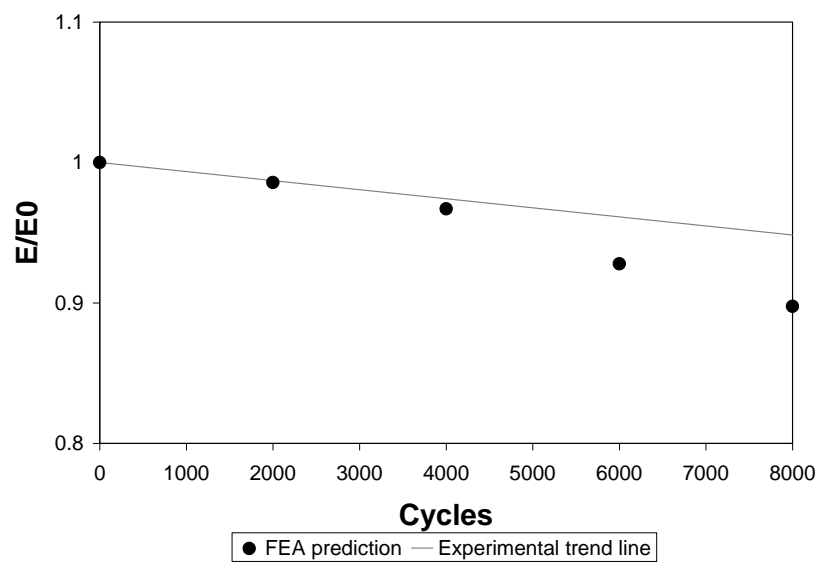

Figure 10. Normalised flexural modulus variation with the degree of damage.

In the next section, the strain distribution derived from the FEA modelling is used to predict the reflected spectra and comparisons are made with experimental results.

\subsubsection{Prediction of spectra and comparison with experimental results}

To predict the reflected spectra, longitudinal strains at the physical location of the CFBG sensor derived from the FE models were input to the software OptiGrating ${ }^{\circledR}$. Figure 11 shows the predicted reflected spectra corresponding to loads of 0.5 and $1 \mathrm{kN}$. The general shift of the reflected spectra to higher wavelength values is the expected consequence of the higher longitudinal strains at the sensor location for the higher applied flexural load. The perturbations in the spectra at $A$ and $B$, and at $A^{\prime}$ and $B^{\prime}$, correspond to the positions of the high strains at the resin-rich regions between the repair and the parent material, at $20 \mathrm{~mm}$ and $40 \mathrm{~mm}$, respectively, from the low-wavelength end of the sensor. The difference in sensor response at $A$ (and $A^{\prime}$ ), compared to $B$ (and $B^{\prime}$ ) is believed to be related to the position of the strain perturbation within the sensor length.
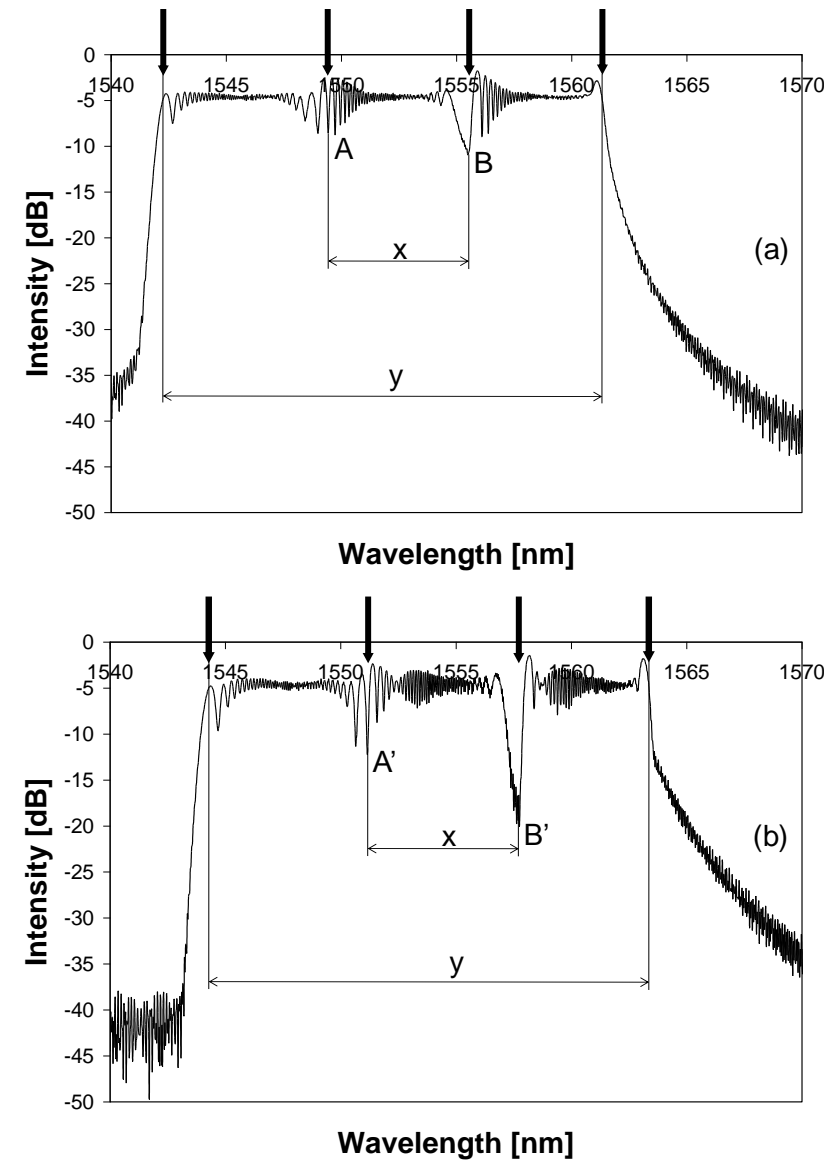

Figure 11. Reflected spectra for undamaged (repaired) panel loaded at (a) 0.5 and (b) $1 \mathrm{kN}$.

During the experimental work described below, the sensor fractured at $A$ and $B$ at an early stage in fatigue as a consequence of the fracture of the overply at the high strain concentrations at those points. Consequently, it makes sense to investigate the reflected spectra for a sensor which extends only over the length from $0 \mathrm{~mm}$ to the first resin-rich region i.e. at position $A$ which is $20 \mathrm{~mm}$ from the low-wavelength end (the sensor was interrogated from this end). Figure 12 (a) shows the predicted reflected spectrum for a sensor that has fractured at point $A$ in a repaired coupon with a fatigue crack that has grown $1.7 \mathrm{~mm}$. This spectrum is compared with the original spectrum for a sensor that has not fractured in a repaired panel without any fatigue damage. The distance $y$ in the figure shows the location of the resin-rich interface in the repaired undamaged coupon, which is at a distance of $20 \mathrm{~mm}$ from the low-wavelength end of the panel, which of course corresponds to $1 / 3$ of the sensor length and also to $1 / 3$ of the spectral bandwidth (i.e. to about 7 $\mathrm{nm})$. Figures 12(b) to 12(d) also show the original repaired spectra but now compared to the spectra for fatigue crack lengths of $2.3 \mathrm{~mm}, 4 \mathrm{~mm}$ and $4.7 \mathrm{~mm}$. It is clear that the distance marked $x$ on these figures is reducing with increasing fatigue crack length. This, of course, is a consequence of the changes in the strain distributions shown in Figure 8 and the stress shielding caused by the fatigue cracks has been discussed already with reference to Figure 9. 

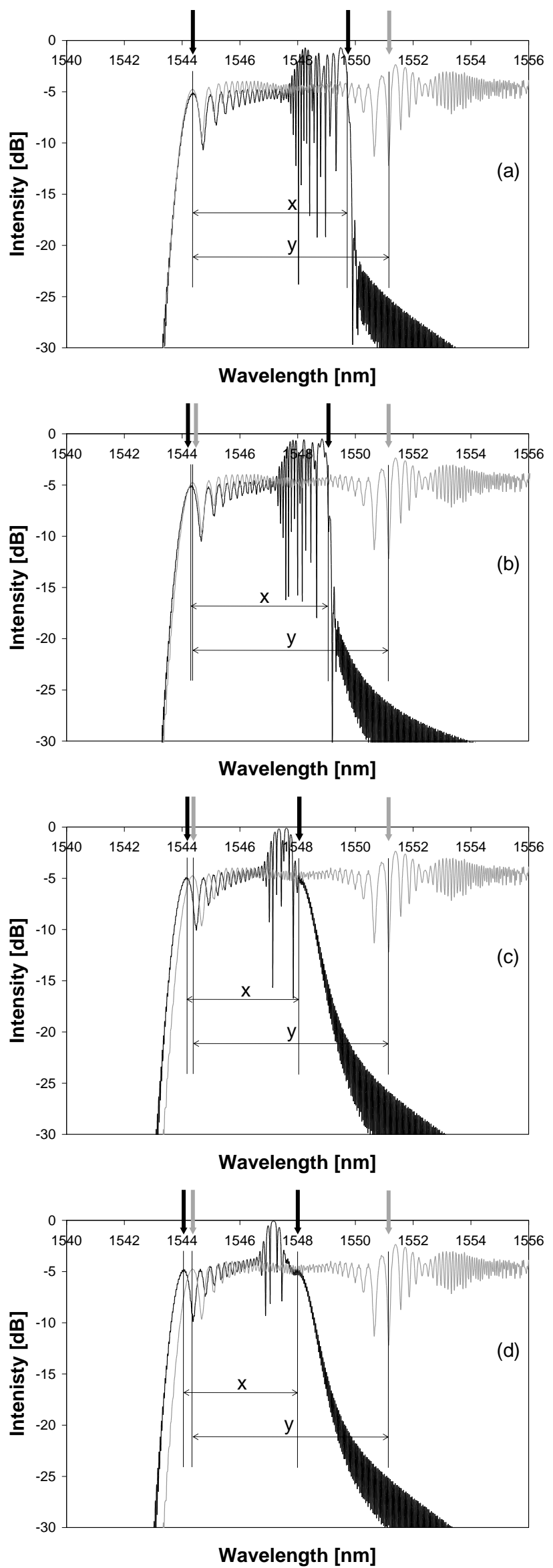

Figure 12. Predicted reflected spectra for different degrees of damage: (a) 1.7, (b) 2.3, (c) 4.0 and (d) $4.7 \mathrm{~mm}$ - at $1 \mathrm{kN}$ load.

Experimentally recorded reflected spectra from the repaired panel subjected to quasi-static loads of 0 $\mathrm{kN}, 0.5 \mathrm{kN}$ and $1 \mathrm{kN}$ before fatigue loading are shown in Figure 13. At this point, the CFBG sensor still remains intact ( $60 \mathrm{~mm}$ long), and the position of the strain concentration at $A$ and $B$ can clearly be seen in the spectra. It is also clear, however, that the differences expected from the predictions within Figure 11 for positions $A$ and $B$ are not reproduced in detail in the experimental results.
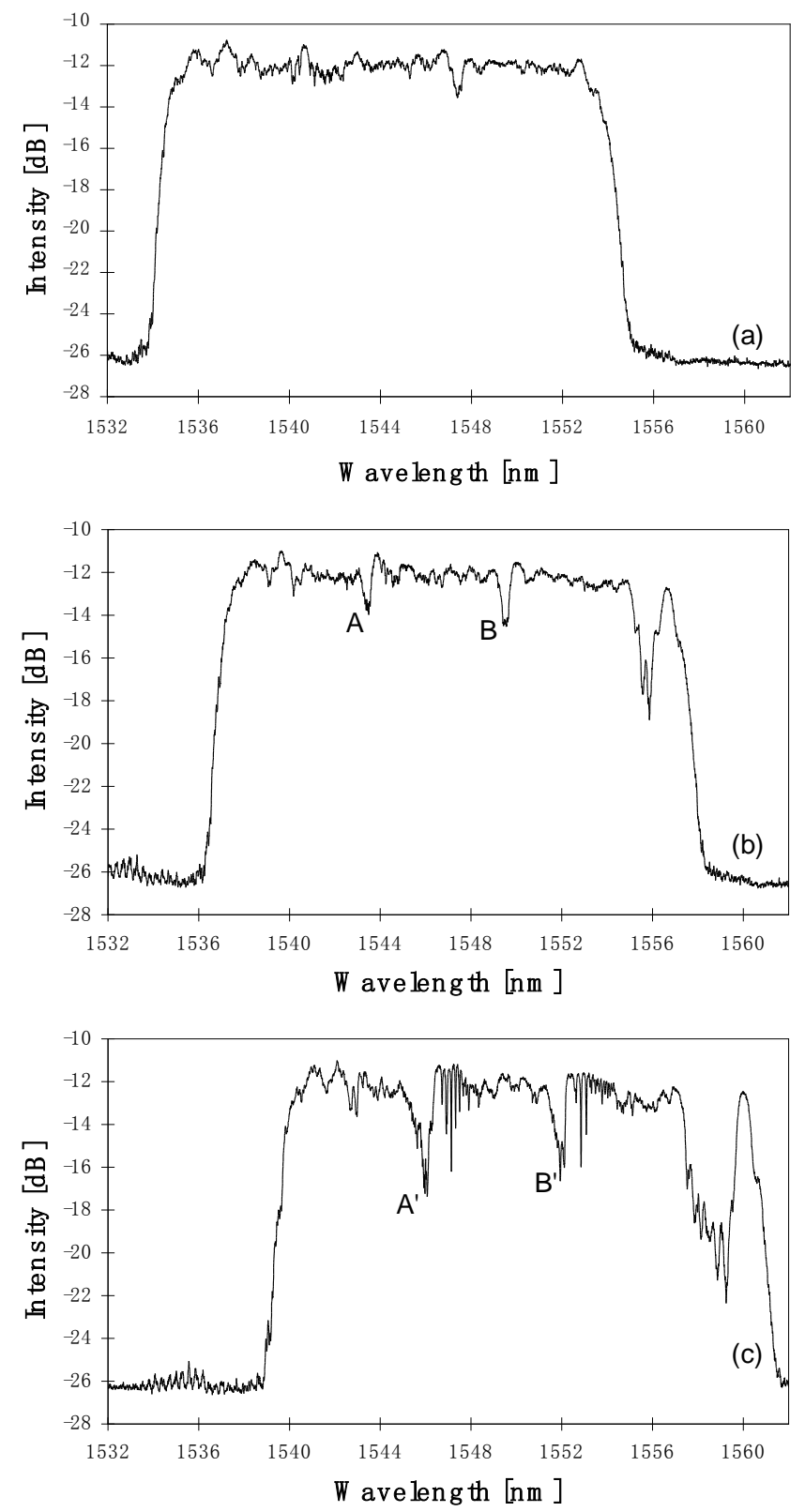

Figure 13. Reflected spectra of the undamaged panel at (a) 0 , (b) 0.5 and (c) at $1 \mathrm{kN}$.

Figure 14 shows experimentally recorded reflected spectra for increasing fatigue crack lengths, from $1.7 \mathrm{~mm}$ at 1000 cycles to $5.8 \mathrm{~mm}$ at 18,000 cycles. By 1000 cycles, the sensor had already fractured at the interface between the scarf repair and the parent material (i.e. at position $A$ and $B$ ). The qualitative changes in the shape of the reflected spectra are in reasonable agreement with the predictions in Figure 12; i.e. the high-wavelength end of the reflected spectra shifts to lower wavelengths as the fatigue crack length increases. The temperature of the specimen was not recorded during these experiments, and there have been a small temperature rise as a consequence of the cyclic 
loading of the specimen. However, it should be pointed out that temperature compensation is not required when making measurements of damage initiation and growth of damage using CFBG sensors. This is because any increase in the temperature of the specimen causes modifications to the reflected spectra which are in the same proportion for all parts of the spectrum (providing the temperature changes are uniform, of course).

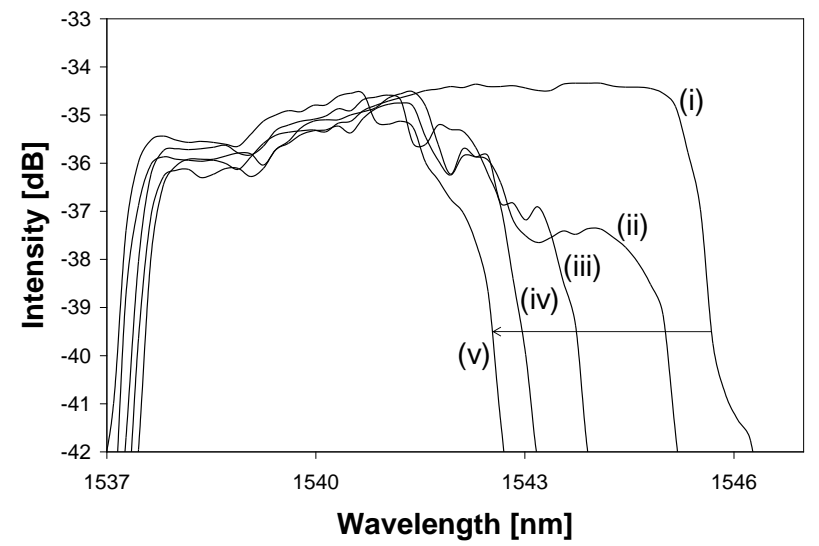

Figure 14. Experimentally measured reflected spectra for increasing crack lengths: (i) 1000, (ii) 10000, (iii) 11000, (iv) 12000, (v) 18000 cycles - at $1 \mathrm{kN}$ load.

\section{CONCLUDING REMARKS}

Fatigue crack growth in a scarf-repaired transparent GFRP coupon (fabricated from sixteen plies of eight-harness satin fabric and epoxy resin) has been characterised in terms of modulus reduction and damage development. During flexural fatigue in four-point bending, damage developed in the form of cracks within the small resin-rich region between the scarf repair and the parent (or host) material. Modulus reductions derived from a finite-element analysis of the damaged repaired panel were in reasonable agreement with the experimental measurements.

The finite-element modelling was also used to predict the expected changes in the reflected spectra of a CFBG sensor embedded between the $16^{\text {th }}$ ply of the parent material and the overply used in the repair. The changes in the predicted reflected spectra as a function of increasing fatigue crack length were in good qualitative agreement with the experimental measurements.

\section{ACKNOWLEDGEMENTS}

The authors would like to thank the Portuguese Foundation for Science and Technology for supporting RLR through the grant SFRH/BD/65729/2009.

\section{REFERENCES}

Breitzan, T.D. et al., 2009. Optimization of a composite scarf repair patch under tensile loading. Composites. Part A, Applied science and manufacturing, 40(12), pp.19211930.

Capell, T.F. et al., 2009. Detection of defects in as manufactured GFRP-GFRP and CFRP-CFRP composite bonnded joints using chirped fibre Bragg grating sensors. Plastics, Rubber and Composites, 38.

Kyriazoglou, C. \& Guild, F.J., 2005. Quantifying the effect of homogeneous and localized damage mechanisms on the damping properties of damaged GFRP and CFRP continuous and woven composite laminates--an FEA approach. Composites Part A: Applied Science and Manufacturing, 36(3), pp.367-379.

Palaniappan, J. et al., 2008. Disbond growth detection in composite-composite single-lap joints using chirped FBG sensors. Composites Science and Technology, 68(12), pp.2410-2417.

Palaniappan, J. et al., 2007. Changes in the reflected spectra of embedded chirped fibre Bragg gratings used to monitor disbonding in bonded composite joints. Composites Science and Technology, 67(13), pp.2847-2853.

Pinto, A.M.G. et al., 2010. Numerical evaluation of threedimensional scarf repairs in carbon-epoxy structures. International Journal of Adhesion and Adhesives, 30(5), pp.329-337.

Ridha, M., Tan, V.B.C. \& Tay, T.E., 2011. Traction-separation laws for progressive failure of bonded scarf repair of composite panel. Composite Structures, 93(4), pp.12391245 . 